\title{
Investigación y restauración en el Alcázar de Sevilla
}

\author{
Research and restoration in the Alcazar of Seville
}

\author{
A. Almagro $*$ (*)
}

RESUMEN

Las intervenciones que durante estos últimos años se han llevado a cabo en el Alcázar de Sevilla coordinadas desde la Escuela de Estudios Árabes (CSIC) constituyen un interesante caso de interrelación entre restauración, investigación histórica, aplicación de técnicas analíticas y difusión de los resultados. Las acciones inter-disciplinares llevadas a cabo por un extenso y variado grupo de investigadores y profesionales con la referencia constante a los valores históricos del monumento han permitido lograr junto a importantes resultados en su conservación física, avances significativos en el conocimiento de su historia y su significado.

Usando siempre como base una rigurosa planimetría fotogramétrica, se han recuperado importantes vestigios originales, se han consolidado y restaurado partes especialmente significativas y se han realizado reconstrucciones virtuales como resultado de la investigación histórica.

\section{SUMMARY}

The interventions that have been accomplished in the last years at the Alcazar of Seville, coordinated by the School of Arabic Studies (CSIC), are an interesting case that shows the relations among restoration, historic research, application of analytic techniques and diffusion of the results. Interdisciplinary actions carried out with the constant reference to historical values of the monument by a large and varied group of researchers and professionals have allowed not only important results regarding its physical conservation but also significant advances in the knowledge of its history and meaning.

Using always rigorous photogrammetric plans as a basis, important original remains have been recuperated, some significative parts have been consolidated and restored and virtual reconstruction have been produced as the result of the historic research.

Keywords: Restoration; research; dissemination; architecture of al-Andalus. 


\section{INTRODUCCIÓN}

El Real Alcázar es sin duda el principal edificio civil de la ciudad de Sevilla y constituye un monumento de gran complejidad en volúmenes, cronología y funcionalidad. Históricamente, ha sido sede de dignatarios y príncipes musulmanes y, desde 1248 hasta nuestros días, corte de los reyes castellanos, y después de España, en la ciudad hispalense. Desde 1931 es propiedad municipal aunque continua siendo Residencia Real, y hoy se usa como lugar de celebración de actos protocolarios municipales y de otros órdenes, foro cultural, aula universitaria y monumento turístico. Desde 1987 está inscrito en la Lista del Patrimonio Mundial Cultural y Natural de la UNESCO. Está gestionado por el Organismo autónomo municipal Patronato del Real Alcázar.

La atención que el Patronato siempre ha dispensado a la conservación del monumento, le ha llevado a menudo a proponer la colaboración de diversas personas y organismos en esta tarea, como forma de garantizar una acción rigurosa en su mantenimiento, rehabilitación y restauración. Por este motivo, desde 1997 se han firmado con la Escuela de Estudios Árabes (EEA) del Consejo Superior de Investigaciones Científicas toda una serie de Convenios de colaboración con distintos objetivos.

Desde hace algo más de veinte años, en la EEA venimos combinando la labor de investigación sobre arquitectura islámica, y en especial andalusí, con las labores de conservación y restauración, desde la firme convicción de que no puede hacerse una labor eficaz y válida de conservación si no es sobre la base del conocimiento del monumento, tanto en lo que atañe a sus aspectos materiales como a aquellos intangibles como su historia y sus significados. Pero tampoco puede hacerse una labor eficaz de investigación si no se aprovechan ocasiones únicas como las que proporcionan las actuaciones de restauración, cuando se dispone de medios auxiliares para llegar a zonas normalmente no accesibles o se pueden ver partes ocultas al eliminarse enlucidos, estructuras adosadas, elementos de cubrición, etc., que en situaciones normales nos impiden analizar gran cantidad de detalle muchas veces fundamentales para conocer el monumento y su historia.

Por este motivo siempre hemos considerado que las intervenciones de restauración deben ir más dirigidas en este sentido que en el de la creación de nuevas arquitecturas sobrepuestas a las existentes, para no generar nuevos conflictos que vengan a superponerse a los que el propio monu- mento ya plantea. Por este motivo, nuestras actuaciones siempre parten de la búsqueda de conocimiento sobre el bien en el que intervenimos, y dentro de él, tiene una singular importancia el análisis formal y métrico realizado a partir de una planimetría rigurosa y fiable que resulta además útil e imprescindible en actuaciones sucesivas.

Pero tampoco podemos olvidar que el conocimiento adquirido en la investigación debe ser transmitido y difundido, y no sólo a los investigadores o profesionales de la restauración a través de publicaciones científicas especializadas, sino también y de un modo especial a la sociedad en general, que es la depositaria del legado histórico que constituye el Patrimonio y que es además quién, en la mayor parte de los casos, paga nuestra actividad mediante sus impuestos. Por este motivo también venimos prestando especial atención a esta actividad que generalmente hemos ido realizando con el recurso de las nuevas tecnologías y especialmente con las recreaciones y reconstrucciones virtuales de los monumentos cuando han sufrido destrucciones o transformaciones que impiden contemplarlos en su forma primitiva.

\section{LEVANTAMIENTO PLANIMÉTRICO Y ESTUDIOS HISTÓRICOS}

La primera labor realizada en el Alcázar consistió precisamente en el levantamiento planimétrico del conjunto arquitectónico mediante técnicas fotogramétricas, aprovechando la larga experiencia en este tipo de trabajos del personal investigador y auxiliar de la Escuela así como los equipos e instrumentos técnicos con que cuenta. Durante tres campañas, entre 1997 y 1999 se acometió la realización de secciones y alzados de las distintas partes del Alcázar utilizando de forma prioritaria sistemas fotogramétricos por considerarse los más idóneos para este tipo de trabajos ya que permiten operar sin apenas medios auxiliares (andamios, grúas, etc.), con períodos muy reducidos de trabajo de campo, y con una gran homogeneidad en la precisión y en la densidad de información a plasmar en los dibujos, especialmente en casos como el que nos ocupa en que la decoración tiene características singulares.

Conjuntos como el del Patio de las DonceIlas, con sus grandes paños de sebka (trama de rombos) de yesería, o del Salón de Embajadores con la media naranja de lazo que lo cubre son difícilmente medibles y representables sin el recurso a las técnicas fotogramétricas y a los sistemas actuales de dibujo asistido por ordenador que nos permiten incluso la generación de modelos tridimensionales susceptibles de ser visualizados en distintas formas, proyecciones y escalas. 
Resultado de todos estos trabajos ha sido una completa colección de planos que, sin duda, posibilita acercarnos al más exhaustivo conocimiento gráfico con que se ha podido contar hasta ahora del conjunto y que han sido publicados en forma de una carpeta de gran formato (1) conteniendo 40 láminas con planos generales y de detalle (Figuras 1-3).

Sirviendo esta información gráfica como base, se han ido posteriormente desarrollando otros trabajos de investigación que han permitido aumentar el conocimiento sobre el monumento y su historia. Merece destacarse el estudio e interpretación realizado sobre el Ilamado Patio del Crucero, un interesantísimo edificio integrado en el Alcázar, y que resalta tanto por las singularidades de lo construido a lo largo de su historia, como por el propio proceso de transformación que se ha ido produciendo en él. Puede decirse que todas sus fases presentan una indudable calidad arquitectónica, pero cada acción sucesiva ha ido enmascarando las fases anteriores hasta hacerlas difícilmente identificables y comprensibles para el espectador. Tras el estudio y la correspondiente publicación científica de los resultados (2), se propuso a la Dirección del Alcázar mostrarlos mediante un sistema audiovisual. Así, en 2001 se realizó en la Escuela de Estudios Árabes del CSIC un sistema que integraba tanto una película explicativa del edificio y de su proceso de transformación, como la posibilidad de un recorrido interactivo por las distintas fases de existencia del Patio del Crucero y el Palacio Gótico (Figura 4). La finalidad del mismo era explicar a los visitantes las formas que este conjunto presentó a lo largo de su historia en sus tres fases principales: palacio islámico, reforma gótica y reforma barroca, haciendo comprensibles las transformaciones espaciales y conceptuales sufridas por esta zona del Alcázar. El resultado del trabajo comprendía un puesto de presentación audiovisual con la aplicación específicamente realizada para este fin, que ha sido además publicada en formato de CD (3) , tanto en versión española como inglesa.

Esta labor de divulgación ha continuado con la realización de otro trabajo similar, más ambicioso puesto que abarca a la totalidad del Alcázar y que tiene por objeto mostrar el conjunto tal y como estuvo diseñado en el momento quizás más singular de su historia, cuando se define en gran medida su actual estructura. Este momento corresponde al reinado de Pedro I de Castilla, entre 1350 y 1369. Dentro de un gran proyecto de reordenación del recinto, este monarca levantó el palacio
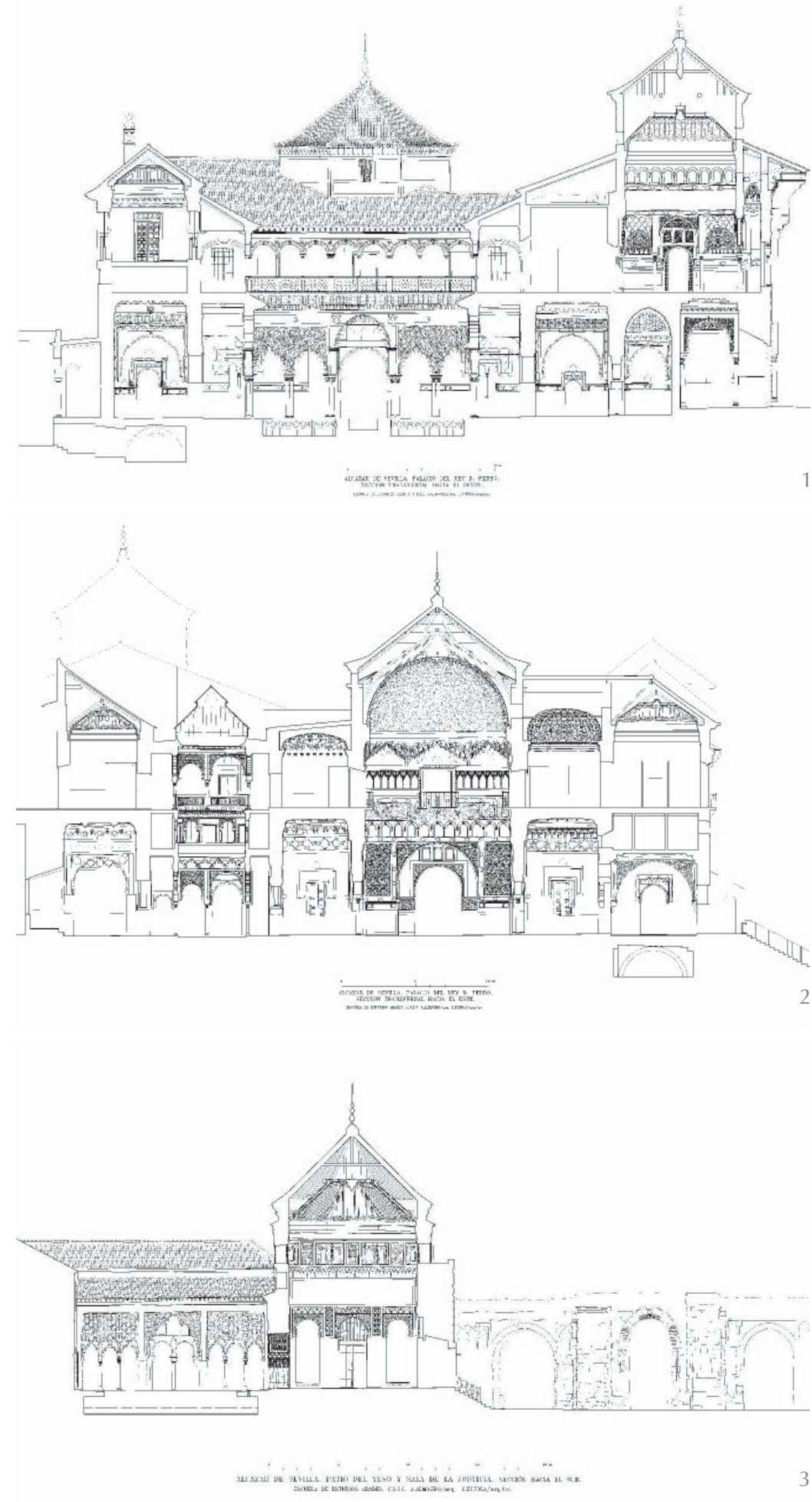

conocido por su nombre que fue desde entonces el núcleo de la residencia real. Con motivo de la celebración en 2006 de una gran exposición sobre Ibn Jaldún, personaje de gran relevancia histórica y que fue embajador ante Pedro I del sultán nazarí Muhammad V, la Escuela de Estudios Árabes recibió en encargo de hacer un audiovisual reconstruyendo el Alcázar de ese momento y que presenta la forma que tuvieron los distintos edificios en esa época (Figuras 5 y 6) (4).
1. Sección transversal del palacio de Pedro I en el Alcázar de Sevilla.

2. Sección por el Salón de Embajadores y Patio de las Muñecas.

3. Sección de la Sala de la Justicia y Patio del Yeso. 
4. Reconstrucción virtual del patio del Crucero en época de Alfonso X.

5. Reconstrucción virtual del Alcázar de Sevilla en el siglo XIV.

6. Reconstrucción virtual del Patio de la Montería con la fachada del palacio de Pedro I.

. El patio de las Doncellas antes del descubrimiento del jardín medieval.
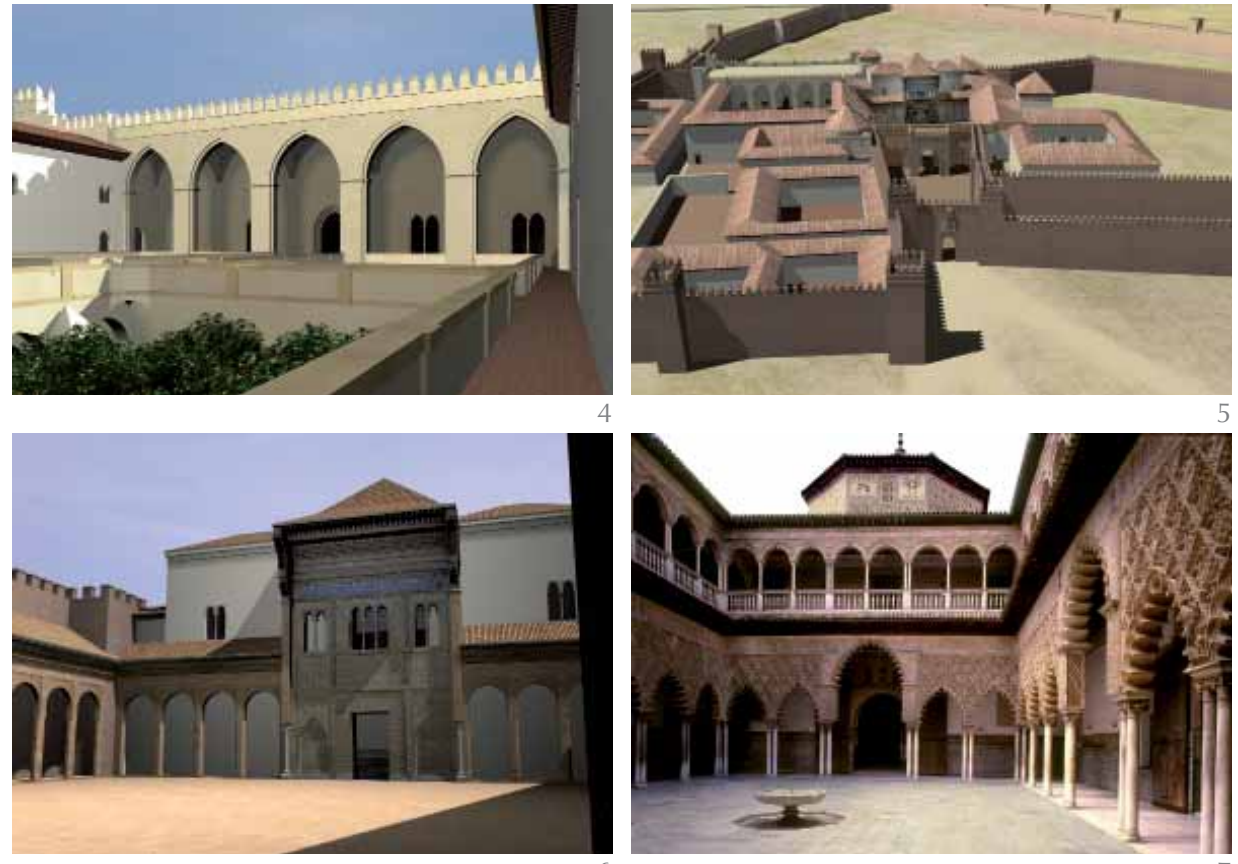

\section{RECUPERACIÓN DEL JARDÍN DEL PATIO DE LAS DONCELLAS}

\section{Problemática y criterios}

En el curso de las excavaciones arqueológicas dirigidas en el verano de 2002 por el Dr. Miguel Ángel Tabales, aparecieron los restos del jardín concebido para ocupar la zona descubierta del patio principal del palacio de Pedro I en el recinto del Alcázar sevillano, que constituyó un hallazgo de singular relieve (5). Pese a que se esperaba la existencia de un jardín de acuerdo con las noticias trasmitidas por algunos documentos del siglo XVI, la contundencia y singularidad del diseño puesto a la luz podemos decir que supuso toda una sorpresa. La importancia del hallazgo, por los valores arquitectónicos que encierra y por lo que nos aporta al conocimiento del propio monumento y de los gustos artísticos de su constructor, movió al Patronato del Real Alcázar a plantear su recuperación como modo de enriquecer la realidad multitemporal y multicultural que encierra este singular monumento. Esta operación conllevaba, evidentemente, un cambio bastante sustancial de la imagen del patio por lo que era necesario valorar su conveniencia.

Diversas consultas y reuniones abordaron los problemas y dificultades que presentaba el proyecto. La primera cuestión que se planteó era la conveniencia o no de recuperar la forma primitiva del patio desenterrando en su totalidad el jardín original. Resulta evidente que la trasformaciones realizadas entre el momento de la construcción del palacio y el siglo XVI y que condu- jeron a la eliminación final del jardín y de la alberca situada en su centro, no fue una mera intervención de conservación sino que debe considerarse una trasformación en el concepto del propio palacio, acorde con la reforma general que se realizó en él a lo largo del siglo XVI (6) (Figura 7).

La recuperación de la primitiva disposición medieval, con el jardín y la alberca se justifica en tanto en cuanto el patio que hoy contemplamos ya no corresponde a ninguna época concreta. Es el fruto de considerar el palacio como un edificio histórico, que materializa toda la evolución que a lo largo del tiempo ha quedado en él registrada y en muchos casos puesta en evidencia con las actuaciones restauradoras. Exhumar el jardín medieval suponía enriquecer con un elemento fundamental de su propia naturaleza histórica, esa superposición de fases y estados, haciendo más visible si cabe el proceso de transformación que sobre él se ha desarrollado. El valor evocador que el jardín aporta a la comprensión de la forma primitiva del palacio, que sin menospreciar las aportaciones posteriores, es la que confiere el carácter sustancial al edificio, justificaba sobradamente una actuación de este tipo.

Por otro lado, la intervención ha sido mínima y puede considerarse fácilmente reversible. Por el estado de los restos exhumados podemos asegurar que cuando se procedió a solar de mármol el patio sólo se eliminó el primitivo pavimento, sin apenas tocar los muros perimetrales de los arriates y de la alberca. Por tanto, la obra realizada fue muy limitada, sin ninguna laguna en cuanto al conocimiento de la forma primitiva. 


\section{Descripción de la intervención.}

Se sabía, por la excavación realizada durante el verano de 2002 que el relleno de los arriates del jardín no presentaba una estratigrafía relevante ni aportaba materiales de interés. Su excavación no presentó más dificultad que la generada por su sólida compactación (Figura 8).

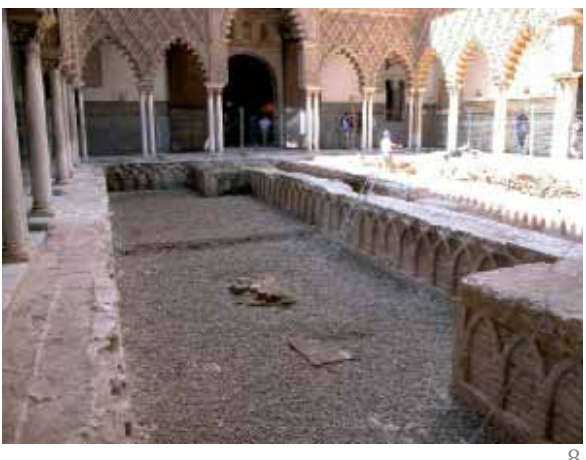

Posteriormente se realizaron una serie de sondeos arqueológicos en las zonas de jardín para analizar las estructuras anteriores a la construcción del palacio (7). También se realizaron sondeos en el pavimento de la alberca y en las zonas macizadas de sus extremos con el fin de determinar la forma y disposición con que fue diseñada.

Parece que la alberca se proyectó inicialmente con más profundidad de la que hoy tiene a juzgar por la presencia de orificios para el riego del jardín a un nivel más bajo que e fondo que ahora presenta. Los sondeos realizados por debajo del pavimento de la alberca buscando la localización de los orificios de los atanores dispuestos para el riego pusieron de manifiesto que nunca llegó a existir un pavimento a ese nivel más profundo (Figura 9), lo que parece indicar que este dispositivo inicialmente pensado para desaguar la alberca y regar el jardín nunca llegó a funcionar, pues una reforma muy temprana, realizada sin haber llegado a rematar la alberca con un solado y los consiguientes enlucidos, hizo que éste se situara a una cota más alta, condenando los orificios inicialmente previstos para la salida del agua. Los ensanchamientos que presentaba en los extremos fueron ma-

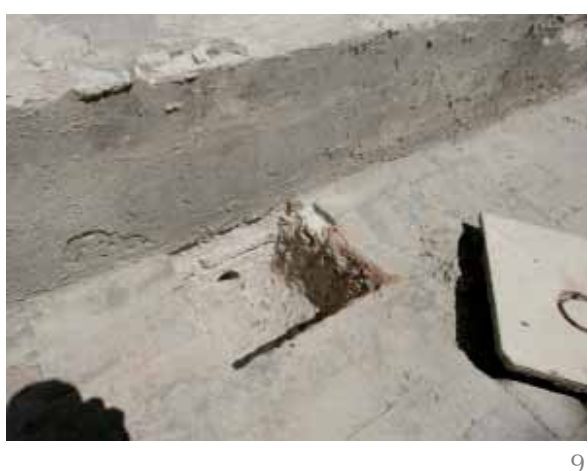

cizados con fábrica de ladrillo y mortero de cal, parece ser que en el mismo momento en que se elevó su suelo. Las catas realizadas en las juntas entre la fábrica inicial y la de reIleno mostraron que estos ensanchamientos tampoco llegaron a estar enlucidos y que por tanto, la forma inicial del estanque nunca estuvo en uso.

Esta trasformación de la alberca plantea la incógnita de saber cuál fue su causa y por que se condenó un sistema previsto para el riego del jardín, muy semejante al que existía en el Patio de la Acequia del palacio del Generalife de Granada (8) . La esterilidad en restos orgánicos que ha puesto de manifiesto la excavación de los parterres del jardín parecerían indicar que éste tuvo una vida muy efímera o que incluso nunca llegara a estar plantado. Por tanto, todo parece indicar que en un momento muy temprano se acometió una primera reforma del patio consistente en enterrar el jardín y sobreelevar el fondo de la alberca reduciendo su volumen. Posteriormente en un momento distinto y tras un uso bastante prolongado de la alberca se acabó por cegarla y sustituirla por una fuente central, operación ya realizada en el siglo XVI.

Por tanto, y a la vista de estas hipótesis, se pensó que la solución que se debía adoptar en el proyecto en lo relativo a la alberca debía ser aquella que resultaba menos conflictiva, y que era conservar el estanque longitudinal tal y como se dispuso en su último momento de funcionamiento marcando en el pavimento, mediante la disposición de los alizares correspondientes, la situación y forma de los ensanchamientos de sus extremos, como finalmente se hizo (Figura 10). El estado de toda la fábrica de los muros del jardín era en general muy bueno, conservando incluso en su mayor parte el tratamiento original de las juntas. En muchas zonas se puede decir que únicamente faltaba el pavimento y el alizar vidriado de los bordes. Sólo en puntos concretos había sufrido roturas causadas por la apertura de zanjas o rozas destinadas a dar paso a distintas canalizaciones relacionadas con la fuente colocada posteriormente en el centro del patio (Figura 7).

La solería de los andenes se ha realizado mediante baldosas de barro cocido cuya fabricación actual resulta fácilmente reconocible (Figura 11). Todos los bordes Ilevan piezas de alizar vidriado en verde oscuro de acuerdo con los fragmentos aparecidos en la excavación. En la disposición de la solería, cuya forma original se desconoce, se ha adoptado la colocación de las piezas a cartabón, formando espiga y de la manera más simple, como modo de evitar encuentros y cortes inconvenientes, y de forma que se reconozca fácilmente su factura actual.
8. El patio de las Doncellas durante el proceso de excavación del jardín.

9. Cata mostrando el orificio dispuesto para el riego del jardín y condenado por la reforma de la alberca del patio de las Doncellas. 

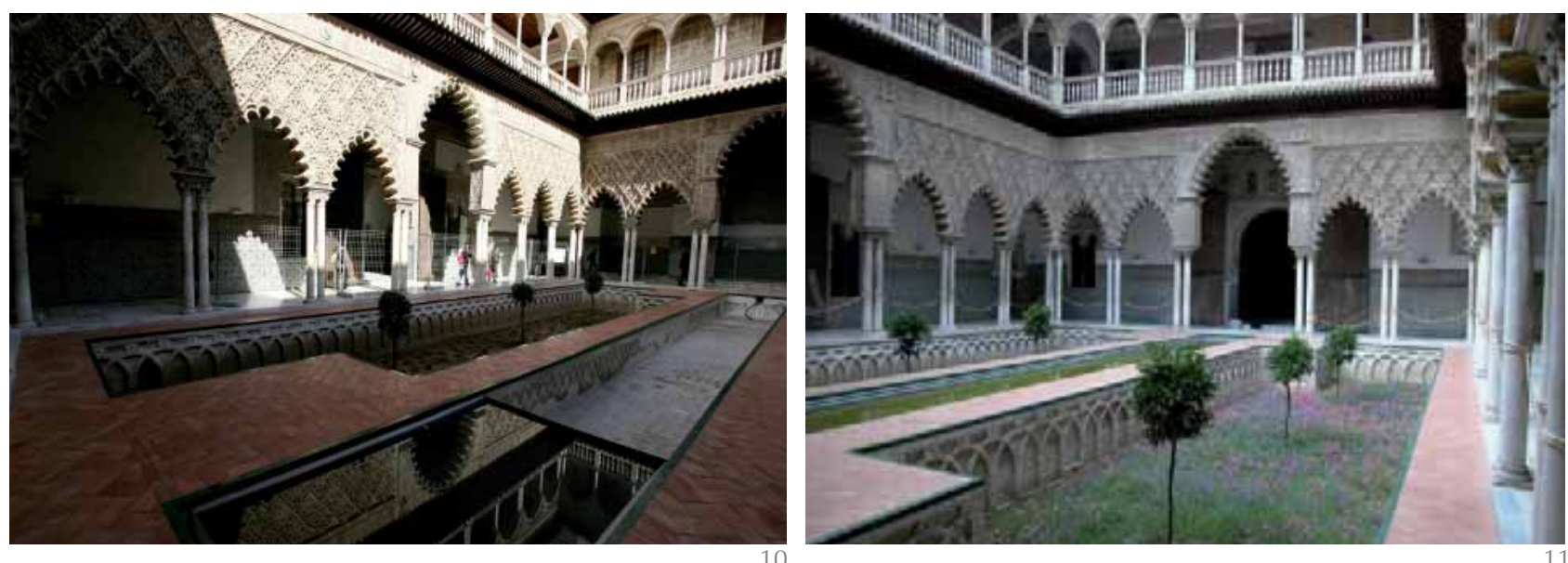

10. Prueba para la construcción del vaso de poliéster de la alberca con el reflejo de la arquitectura en el agua. También se aprecia la solución del pavimento marcando la forma original de la alberca.

11. El patio de las Doncellas tras la recuperación del jardín original.
La alberca longitudinal presentaba restos de pinturas murales en dos capas distintas. La más antigua reproducía un alicatado a base de lazo con estrellas de ocho. De él solo se ha podido recuperar una pequeña zona dejada al descubierto por el enlucido posterior. La decoración más moderna reproduce unas a modo de ondas en color azul, de factura bastante torpe. La aparición de estas pinturas ha puesto en evidencia la dificultad de compatibilizar la conservación de restos materiales de interés con la recuperación de otros valores igualmente importantes, si no más, como son los visuales y ambientales de una obra concebida para disfrute de los sentidos. Desde un primer momento se pensó que la recuperación del jardín no debía limitarse a sus estructuras de fábrica sino que tenía que comprender también aquellos elementos para los que realmente se había realizado: la vegetación y el agua, habida cuenta además de que se estaba interviniendo en un edificio vivo y no en una ruina arqueológica. Hay que tener en cuenta que estas pinturas tuvieron en sus orígenes un carácter efímero, en el sentido de que se consideraba que su deterioro no suponía ninguna pérdida especial y podía reponerse con facilidad. Pero a pesar de su escaso valor artístico, no cabe duda de que constituye un testimonio de singular valor histórico y por tanto de interés.

El relleno de la alberca con agua planteaba serias dificultades a la hora de garantizar la conservación de estas pinturas. Aparecía, pues, el dilema tantas veces presente, de hacer compatible la preservación de la originalidad de unos materiales frente a la recuperación de la originalidad de la idea arquitectónica en la que el agua juega un papel primordial. Tras analizar diversas posibilidades, inclusive el usar agua tratada, se optó por la solución que resulta más fácilmente reversible, colocando dentro del hueco de la alberca un recipiente o vaso construido en fibra de vidrio y poliéster, totalmente independiente de la fábrica original y que deja una pequeña cámara entre sus paredes y la pintura (Figura 10). De ese modo, las pinturas quedan conservadas $y$ protegidas, aunque evidentemente no pueden verse, pero el hueco de la alberca puede contemplarse lleno de agua produciendo los efectos visuales y ambientales deseados.

Aunque en el trascurso de la excavación se tomaron muestras para realizar análisis palinológicos y edáficos del suelo primitivo del jardín, dada la naturaleza del relleno utilizado, con un alto contenido de cal, no se ha obtenido información válida respecto a plantas usadas y su disposición en el jardín. De acuerdo con las informaciones facilitadas por otras investigaciones, en particular las recientemente realizadas en el Patio de la Acequia de Generalife en Granada, parece que este tipo de jardines contó con una vegetación de pradera de flores de pequeño porte y muy escasos elementos arbóreos (9). En el patio de las Doncellas hay indicios de que existiría un tipo de jardín semejante a juzgar por el escaso espesor del suelo vegetal pues las estructuras de muros anteriores aparecen casi a flor del suelo.

Sobre estas suposiciones, se ha realizado la plantación de seis naranjos de pequeño porte (Figura 11) que deberán ser sustituidos por otros nuevos cuando su crecimiento lo haga aconsejable a fin de no perturbar una adecuada contemplación de la arquitectura del patio. El resto del área cultivable se plantó con especies de prado de flores, dejando en los bordes una estrecha franja sin vegetación que se ha rellenado con gravilla para facilitar la evaporación de la humedad del suelo en la cercanía de los muros.

Mediante esta obra se ha puesto en valor un elemento de enorme interés que enriquece nuestro conocimiento del alcázar medieval. Aporta la posibilidad de percibir la forma en que fue proyectada esta residencia regia que, por tratarse de un edificio vivo y que ha sido modificado muchas veces a lo largo de su historia, ha visto alteradas sus formas de uso y el modo de entender su ar- 
quitectura. Pese a que ninguno de los estados por los que pasó podemos hoy revivirlo en solitario, la recuperación del jardín y de la estructura primitiva del patio nos permite imaginar de un modo muy cercano a su realidad, la forma con que se ideó este espléndido espacio, que nos evoca los deseos de ostentación de poder y de goce de una vida placentera para los sentidos buscados por el monarca que lo concibió y que finalmente apenas pudo gozar de él.

\section{RESTAURACIÓN DE LA FACHADA DEL PALACIO DE PEDRO I}

\section{Estudios previos}

Sin duda, el elemento más representativo de todo el conjunto del Alcázar de Sevilla sea la fachada construida por Pedro I para su palacio. Se trata de una pieza emblemática dentro de la arquitectura hispana y seguramente por ello sea la más admirada y reproducida en imágenes de todo el Alcázar (Figura 12).

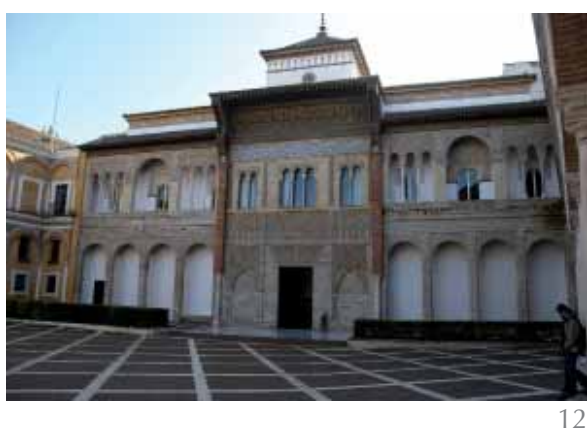

En junio de 2005 el Patronato del Real Alcázar encomendó a la Escuela de Estudios Árabes (CSIC) analizar el estado de conservación de este importante elemento del conjunto y proponer las acciones a desarrollar. Con este motivo se propuso un programa de actuaciones en distintas fases con el fin de lograr el objetivo propuesto de garantizar su conservación futura en las mejores condiciones posibles. De este modo se iniciaron en ese mismo año una serie de estudios tanto históricos como de la situación física de la fachada y de sus materiales, concluidos en el año siguiente. Durante los años 2007 y 2008 se acometió la intervención en el cuerpo central que está integrado por la rica portada pétrea rematada en el soberbio alero policromado. Entre los años 2008 y 2009 se restauró el extremo derecho de la fachada y durante el año 2010 se ha restaurado el lateral izquierdo.

Como actuación previa a la intervención restauradora se emprendió una campaña muy completa de análisis y estudios por parte de un equipo interdisciplinar integrado por grupos de investigadores de la red Temática de Patrimonio Histórico y Cultural del CSIC, de la Universidad de Granada y del INIA, que abordaron su estudio histórico, el de la poli- cromía del alero, de los tipos de madera y su datación, de los materiales pétreos, los materiales cerámicos y morteros y las alteraciones de origen biológico. Los grupos de investigadores pertenecían, además de a la Escuela de Estudios Árabes, al Instituto de Ciencias de la Construcción "Eduardo Torroja" dirigido por $M^{a}$ Teresa Blanco, al Instituto de Geología Económica dirigido por Rafael Fort, de Madrid, y al Instituto de Agrobiología y Recursos Naturales de Sevilla dirigido por Cesáreo Saiz. El grupo perteneciente a la Facultad de Bellas Artes de la Universidad de Granada estuvo dirigido por Víctor Medina y Ana García. Por el INIA intervino Eduardo Rodríguez Trobajo. Esta investigación se ha venido completando con la toma de nuevas muestras durante el proceso de restauración, especialmente de la policromía, con el fin de estudiar las alteraciones cromáticas que ha sufrido la fachada a lo largo de su historia (10) .

El análisis histórico de la fachada del palacio del rey D. Pedro buscaba resolver dos cuestiones fundamentales. Primeramente, determinar cuál fue la forma original que tuvo esta parte del palacio en el momento de su construcción y por otro lado conocer cómo se fueron produciendo las transformaciones sucesivas que a lo largo del tiempo han afectado a su forma, pero sobre todo a la imagen del propio edificio, al tratarse de su elemento más visible.

Dos han sido los métodos básicos utilizados en este estudio. El primero, aplicado fundamentalmente al conocimiento de la forma original de la fachada, ha sido de tipo arqueológico, basado en el análisis de las distintas fábricas y su interrelación, sobre todo, en sus relaciones de antero-posterioridad. El segundo método, aplicado sobre todo a la evolución y transformación de la fachada, ha sido de carácter documental y especialmente iconográfico, después de una exhaustiva recopilación de las imágenes disponibles del Alcázar, que ha permitido conocer con bastante precisión los cambios sufridos por ésta en los últimos tres siglos y medio.

En el transcurso de esta investigación se ha realizado una revisión minuciosa de los camaranchones o espacios residuales que quedan bajo las cubiertas inmediatas a la fachada con objeto de detectar qué elementos pueden ser considerados obra original y cuales añadidos o modificaciones. Debe tenerse en cuenta que estas zonas, por no ser utilizadas ni resultar accesibles habitualmente, suelen presentar un mayor descuido en sus acabados, lo que deja a la luz normalmente rastros de casi todas las transformaciones sin requerir por tanto picar o eliminar los enlucidos (Figuras 13 y 14). Para conocer cual fue la disposición original necesitába-
12. Fachada del palacio de Pedro I después de la restauración. 


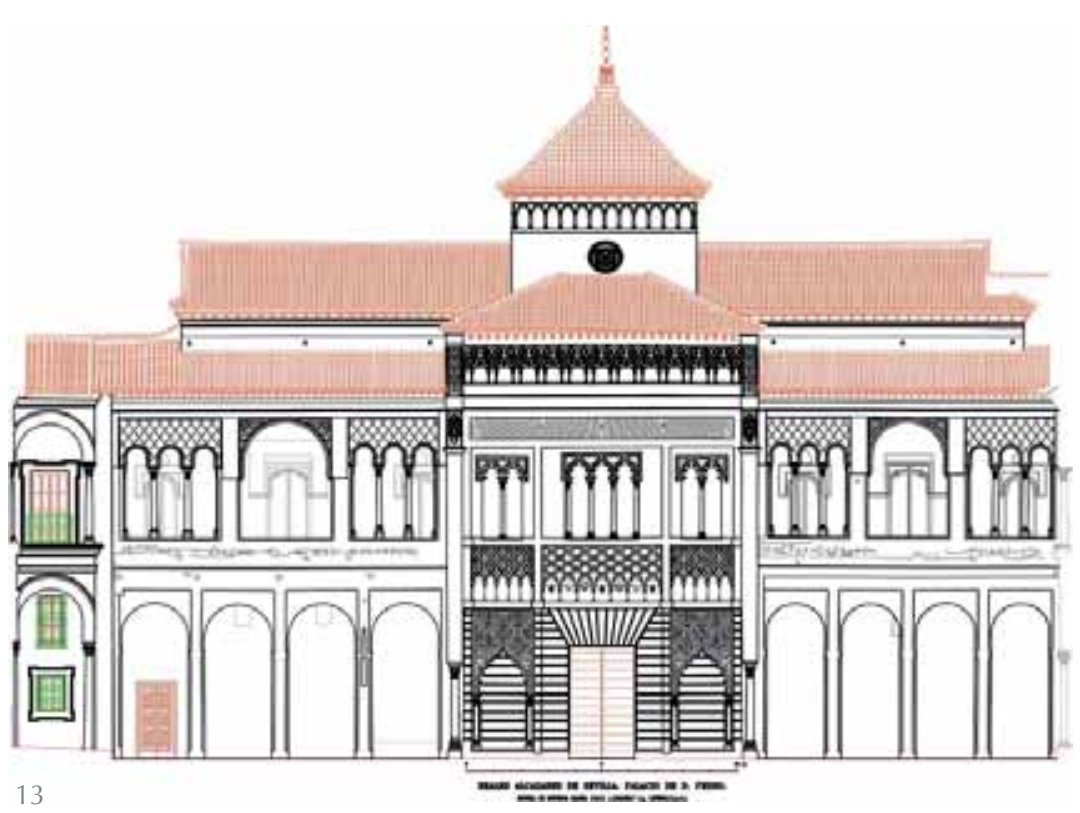

13. Alzado principal del palacio de Pedro I.

14. Primitivas ventanas de la sala de audiencias de la planta alta visibles dentro de los camaranchones de la cubierta. Debajo de ellas se aprecia el canal de desagüe del primitivo tejado.

15. Restos de la cornisa original del cuerpo alto del palacio de Pedro I conservada en los camaranchones actuales.

16. Reconstrucción virtual de las cubiertas originales del palacio de Pedro I.
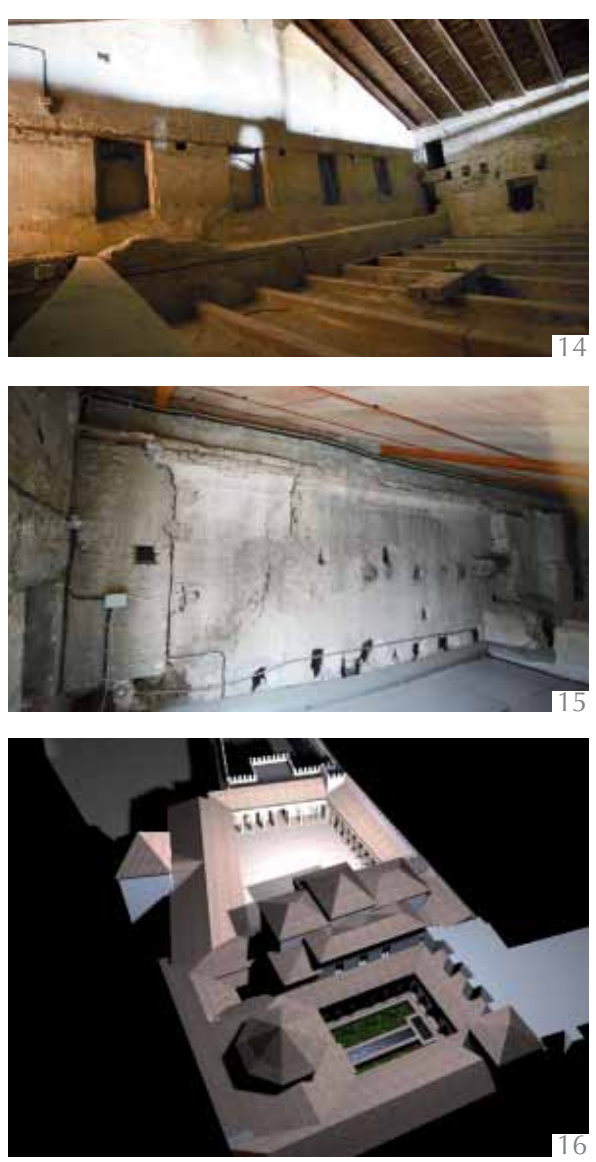

Por estos datos puede afirmarse que las cubiertas de los cuerpos laterales tuvieron disposición de pabellón a cuatro aguas como la de la misma sala de audiencias. También podemos precisar que la sala más occidental de la crujía de fachada tuvo inicialmente un techo ochavado, como lo demuestra la existencia de dos series de cuadrales a distinta altura, independientes de los que existen a nivel del estribo de la cubierta. En otra zona de los camaranchones se conserva otro fragmento de la cornisa original y la prueba de que el actual vestíbulo del piso alto es pieza añadida a las primitivas habitaciones porque para el apoyo de su armadura, que lleva las armas de los Reyes Católicos, se abrió una roza en el muro original de cierre del cuerpo alto y su enlucido.

Otra cuestión que ya de tiempo se ha venido considerando es que las galerías superiores de los cuerpos laterales son fruto de una modificación posterior. La ampliación de la planta alta con la sala del actual vestíbulo y el hecho de que hayamos podido comprobar que mientras los pilares de los pórticos inferiores inmediatos a la portada están perfectamente trabados con ésta, los de las galerías superiores están simplemente adosados, permiten corroborar esta hipótesis. Todo esto da base para plantear una propuesta sobre la forma que presentaba la fachada del palacio en su primera concepción y que representamos en imágenes virtuales (Figura 16). 
La evolución de la fachada a lo largo del tiempo ha podido ser analizada gracias a las fuentes documentales escritas, provenientes fundamentalmente del archivo del Alcázar y estudiadas por diversos autores, y sobre todo mediante la documentación iconográfica que en este caso es especialmente numerosa al ser la fachada el elemento más vistoso y podemos decir "fotogénico" de todo el conjunto.

Para estos estudios han sido también muy útiles los trabajos de dendrocronología desarrollados por Eduardo Rodríguez Trobajo, del INIA. Aunque aún se encuentran en una fase de desarrollo, se puede avanzar que los datos hasta ahora obtenidos respecto de alero son concordantes con la fecha que nos proporciona la propia fachada en su letrero epigráfico, lo que aparte de que nos ratifica la autenticidad de la estructura que ha llegado hasta nosotros, nos confirma la idoneidad de esta técnica para la datación de otras partes para las que existen aún dudas en cuanto a su cronología, y que esperamos que en un futuro próximo puedan irse resolviendo.

\section{Portada central}

La portada del Palacio de Pedro I ocupa la zona central de su fachada norte y está construida principalmente con sillería. Presenta una composición tripartita con tres calles verticales y otras tantas bandas horizontales, separadas por impostas y pilastras lisas y todo ello enmarcado por dos gruesas pilastras de ladrillo apoyadas en columnas de mármol con capiteles de estilo califal. La calle central contiene en su parte baja la puerta, mientras en cada una de las dos caIles laterales hay un arco lobulado apeado en columnas de mármol y del que arrancan paños de sebka.

Esta zona inferior queda rematada por una simple imposta, sobre la que se sitúa una banda de decoración sobre la que se levanta el cuerpo alto con paramentos lisos perforados por ventanas compuestas por vanos geminados en las calles laterales y triple en la central. Sobre las ventanas se dispone un gran registro rectangular compuesto por un a modo de dintel adovelado realizado mediante piezas cerámicas vidriadas de color azul incrustadas en el paramento de piedra y que a su vez forman una inscripción en árabe simétrica respecto al eje de la portada. Todo ello está bordeado por otra inscripción en castellano, en letra del siglo XIV, con el siguiente texto: El mui alto et muy noble et mui poderoso et muy conqueridor Don Pedro por la gracia de Dios rey de Castiella et de Leon maneo (sic por mandó) fazer estos alcaçares et estos palacios et estas portadas que fue fecho en la era de mill et quatrocientos y eos (sic por dos) (año de la era hispánica equivalente a 1364). Por encima de la inscripción se desarrolla el gran alero de madera tallada que remata y protege la portada y que presentan un vuelo de $1.60 \mathrm{~m}$, delimitado por dos grandes ménsulas.

El estado de conservación de la fachada del palacio de D. Pedro era satisfactorio en lo que se refiere a su estabilidad estructural (Figura 17). Sin embargo existían lesiones, que podemos considerar de epidermis, que afectaban de modo negativo a la conservación de este monumento y que requerían un tratamiento adecuado. Este tipo de lesiones eran el fruto de la acción del tiempo como enunciado genérico, aunque todas ellas tenían unas causas más concretas, casi siempre ligadas a las acciones del medio ambiente y a la propia naturaleza de los materiales. Como causas más específicas podemos citar la acción del agua, bien como disolvente o ligada a la de contaminantes contenidos en la atmósfera que producen reacciones químicas sobre los materiales, de los cambios de temperatura que provocan tensiones diferenciales entre éstos, de agentes biológicos, de la acción de los rayos ultravioleta degradantes de los materiales orgánicos, etc.

Estos efectos se han venido produciendo a lo largo del tiempo y han sido atajados de manera prácticamente continua, tratando en unos casos de detener o minimizar las acciones degradantes y en otros casos reponiendo los materiales degradados. Esta labor, que podemos considerar de mantenimiento continuo, se ha venido desarrollando sin apenas soluciones de continuidad, razón por la cual la obra ahora realizada debe considerarse una continuación de este tipo de actuaciones, aunque hoy se hayan añadido a los meros criterios de mantenimiento, los que se derivan de considerar el edificio como monumento histórico, aprovechando además los conocimientos científicos y las posibilidades técnicas de que disponemos en la actualidad.

Las acciones llevadas a cabo se pueden agrupar en dos, de acuerdo con las zonas de actuación y los materiales que en ellas predominan. Por un lado, la intervención en el alero de madera, tallado y policromado, comportó dos tipos de trabajos: por un lado la revisión del estado de la estructura, previo levantamiento del tejado que lo cubre, y por otro la restauración propiamente de éste. La estructura se encontraba en perfecto estado, y tras su limpieza y su tratamiento antixilófagos, se cubrió de nuevo con el tejado después de ser adecuadamente documentada.

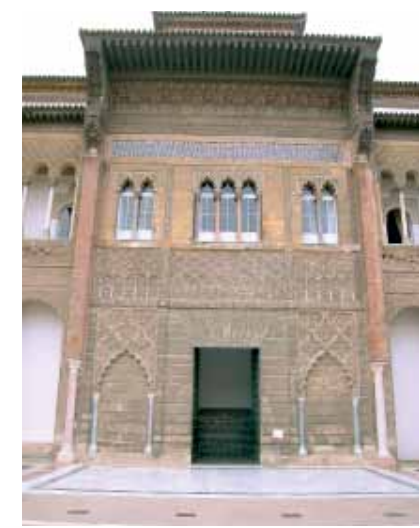

17

17. Portada del palacio de Pedro I antes de su restauración. 

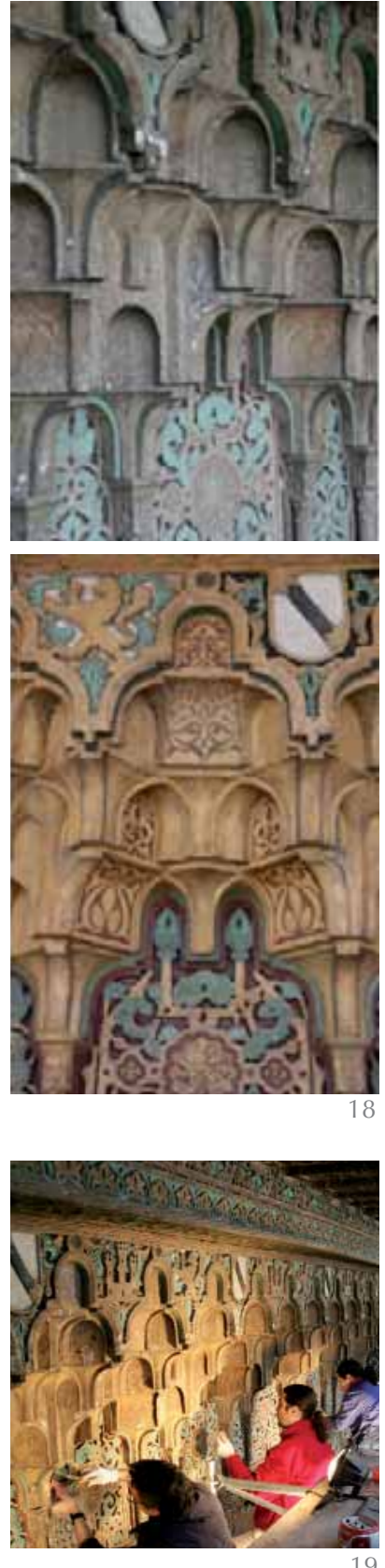

18. Detalle de la policromía del alero antes y después de la restauración.

19. Proceso de restauración del alero.

20. Vista del alero al concluir su restauración.

21. Vista del sofito del alero restaurado.

22. Detalle de una de las ménsulas del extremo del alero después de restaurada.

23. Detalle de la policromía del alero tras su restauración.
La restauración del alero se ha centrado fundamentalmente en su policromía, ya que las maderas se encontraban en general en buen estado, salvo en las caras externas de las ménsulas. En el alero se han podido documentar y detectar numerosas intervenciones cuyo objetivo ha sido siempre restituir el cromatismo que el tiempo iba borrando. $\mathrm{Al}$ menos cuatro operaciones de pintura se pueden rastrear en la documentación escrita conservada y podría incluso suponerse al menos otra más. Los análisis de estratigrafía de la capa pictórica detectan entre tres y siete capas de policromía, que en algunos casos han alterado los colores originales.

El criterio aplicado en la restauración de la policromía ha sido conservador. Ante la práctica imposibilidad de recuperar la capa original que sólo aparecía en zonas especialmente protegidas, resultaba desaconsejable la eliminación de las capas posteriores pues podía quedar el alero sin policromía en amplias zonas, por lo que se optó por consolidar todo lo conservado. La policromía se encontraba muy desprendida, abarquillada y exfoliada y con mucha suciedad adherida (Figura 18).

La restauración ha consistido en la fijación de la capa pictórica al soporte, la limpieza de la policromía y la reintegración de las lagunas que producían excesivo impacto (Figura 19).
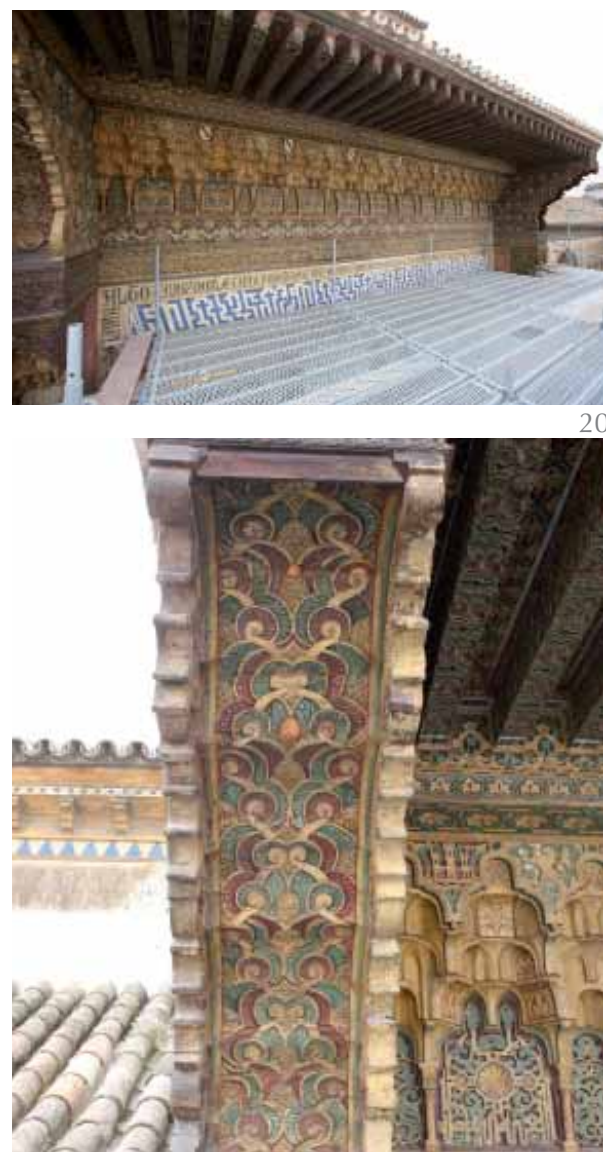

22
Esta reintegración se ha llevado a cabo con técnica de rigatino o rallado fino que permite distinguir con claridad las zonas repintadas en cuanto se observan en proximidad. Finalmente se le ha dado a todo el alero una protección. Todo esto ha permitido recuperar en gran medida la policromía sin que desentone por su excesiva viveza, ya que en su inmensa mayoría corresponde a pintura antigua ya matizada por el tiempo (Figuras 20-23).

Problema distinto y más grave es el que presentaba la piedra de la portada que proviene de dos canteras distintas. Una más porosa y más parecida a la utilizada en otros edificios sevillanos, utilizada en las zonas bajas, no ha presentado ningún problema especial. La otra, de grano más fino, más blanda y de menor porosidad, utilizada para las zonas decoradas ha presentado dificultades mayores. En primer lugar por su alto deterioro manifestado en procesos de exfoliación y desagregación que requerían una consolidación adecuada. Sin embargo, su escasa porosidad hacía desaconsejable el uso de productos sintéticos por la dificultad de penetración, lo que podía provocar que se acentuaran los procesos de deterioro. Por ello se optó también por una acción prudente utilizando exclusivamente productos y técnicas totalmente compatibles con la naturaleza del material.
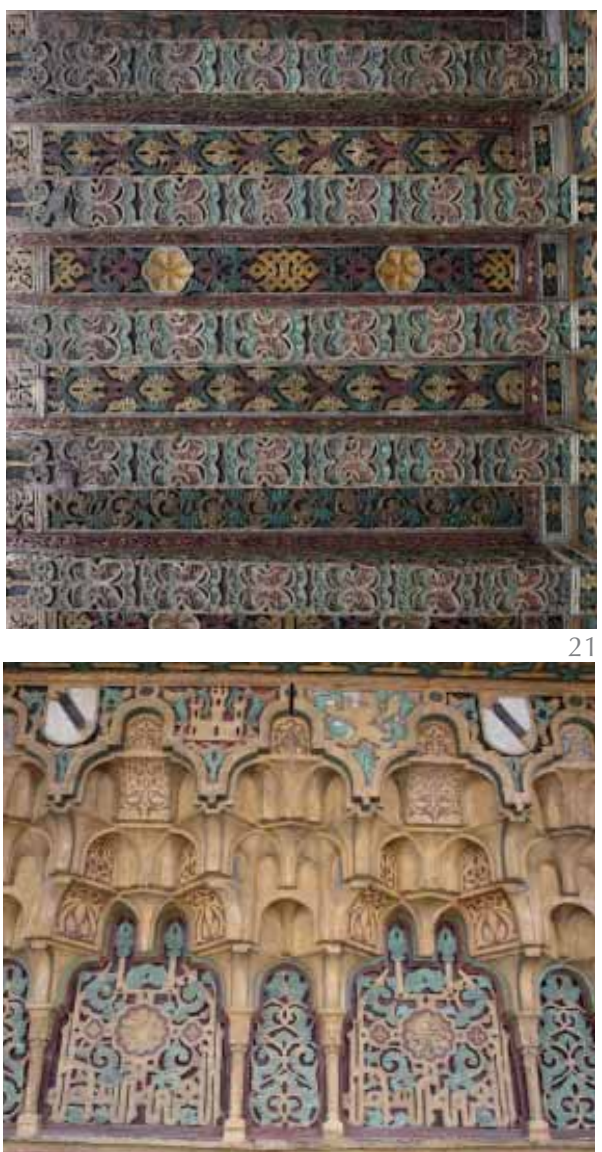
En las fisuras y descamaciones se ha inyectado mortero de cal con micro áridos. Simultáneamente se ha procedido a realizar impregnaciones sucesivas con agua de cal con el fin de dar consistencia a la superficie.

Aunque los resultados no puedan considerarse espectaculares, se ha logrado devolver al material una mayor firmeza, que pese a no alcanzar la de sus orígenes si parece ser suficiente para detener el deterioro por disgregación. En todo caso se considera que este tipo de tratamiento tiene mayores garantías de inocuidad y no será nunca perjudicial, pudiéndose repetir con cierta periodicidad para asegurar la durabilidad de la decoración pétrea. Por ello será necesario en el futuro realizar un seguimiento del comportamiento de la intervención repitiendo los tratamientos de protección en el alero y la piedra cada cierto tiempo.

Previa o simultáneamente, según los casos, se ha realizado una limpieza de la piedra utilizando técnicas de láser (Figuras 24-26) y emplastes de celulosa con bicarbonato de amonio y otros disolventes, aplicados según su estado y solidez.

Otra cuestión que ha sido necesario abordar es la de las pérdidas de material acaecidas tanto en el pasado como recientemente. La fachada, como se ha dicho, ha sufrido múltiples restauraciones, con reintegración de elementos perdidos. En el caso de la decoración pétrea, muchas de éstas fueron realizadas con yeso. Cuando esas reintegraciones estaban en buen estado y no constituían peligro aparente para la piedra original, se respetaron. Cuando estaban desprendidas o constituían claramente falseamiento de las formas originales fueron sustituidas o eliminadas. Las reintegraciones se realizaron con mortero de cal y han seguido el criterio de recomponer aquellos elementos geométricos con formas bien reconocibles y que constituyen parte fundamental en la imagen del monumento. Se ha seguido con ello un proceso mantenido desde antiguo en intervenciones previas. Estas reintegraciones han afectado casi exclusivamente a las formas geométricas de las sebkas o tramas rómbicas. En ningún momento se han reintegrado elementos que son fruto de una mayor creatividad como son los elementos heráldicos de leones, castillos y bandas o de decoración floral. Se limpiaron también todos los elementos de mármol tales como columnas basas, capiteles e impostas.

Los elementos cerámicos que contiene la portada, especialmente los vidriados, han sido objeto igualmente de una limpieza adecuada y de la fijación de aquellas piezas que se encontraban desprendidas. Los alicatados se encontraban, en general, completos por lo que no ha sido preciso realizar ninguna reintegración. Distinto problema era el de su soporte, que originalmente era la propia piedra de la fachada, pero que se encontraba muy reconstruido con morteros, sobre todo de yeso, que presentaban en algunos sitios signos de incompatibilidad con la piedra. Sólo se han eliminado aquellas zonas que se encontraban desprendidas o muy alteradas, sustituyéndolas por un mortero de cal.

La inscripción en letra gótica dispuesta a modo de orla de la geométrica en árabe con forma de dintel adovelado, está realizada con técnica parecida al esgrafiado. Las letras, grabada en hueco en la piedra, está rellenas con mortero coloreado con negro de humo y han sido reparadas y repintadas en numerosas ocasiones. Resultaba difícilmente legible en su totalidad a causa de la suciedad y la pérdida de color de las mismas letras. En este caso, tras la limpieza de la piedra y el relleno, se ha resaltado el color negro de éste con reintegración de las lagunas y reavivado y fijación del color mediante su imprimación con $\mathrm{Pa}$ raloid (Figura 27).

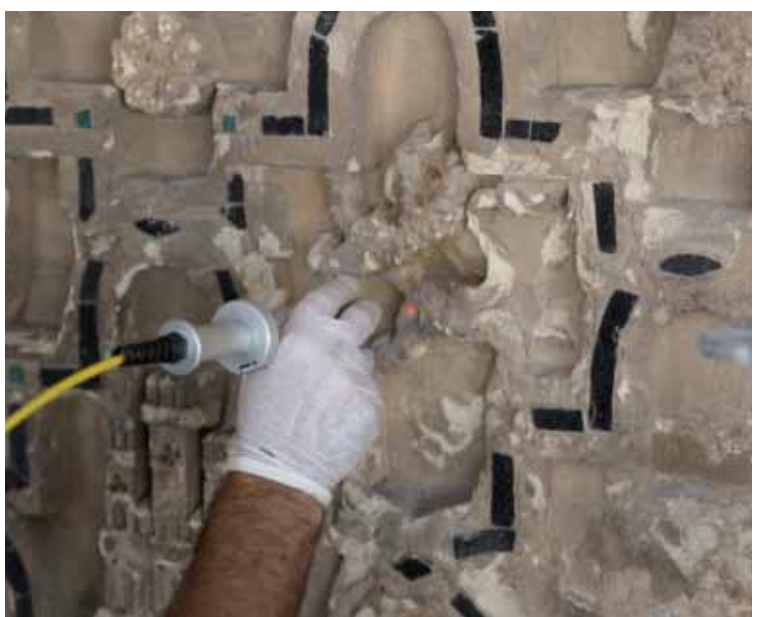

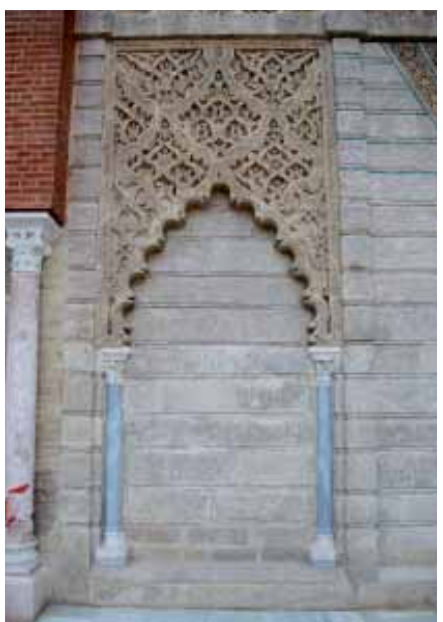

25
24. Proceso de limpieza con láser de la decoración pétrea de la portada.

25. Un detalle de la portada después de la restauración.

26. La misma zona antes de ser restaurada. 
27. Parte superior de la portada con las inscripciones y azulejos.

28. La portada del palacio de Pedro I una vez concluida la restauración.

29. Proceso de restauración del alero del lateral derecho de la fachada.

30. Uno de los casetones del techo de la galería antes y después de la restauración.
Finalmente, también se ha dado una solución adecuada al cerramiento de las ventanas del cuerpo alto de la portada colocando unas simples lunas fijadas a cercos de madera que quedan invisibles desde el exterior (Figura 28).

\section{Laterales de la fachada}

Entre los años 2008 y 2009 se realizó la restauración del lado derecho de la fachada como continuación de la intervención en el cuerpo central y en una tercera fase se ultimó la intervención en el lado izquierdo entre abril y diciembre de 2010.

A diferencia del cuerpo central, los laterales de la fachada no están construidos en piedra sino en ladrillo, yeso y tapia de cal. La zona baja la compone una arquería de ladrillo que en un primer momento se remataba con un alero al nivel del piso alto. Una reforma, seguramente de finales del siglo XV, añadió una galería superior compuesta por arcos y yeserías apoyados en pilares de ladrillo y columnas de mármol. Seguramente en ese momento se tapió la arquería del piso bajo al abandonarse el proyecto inicial que preveía extender las arquerías a todos los lados del patio. A juzgar por los datos obtenidos en los análisis ahora realizados, es probable que el alero primitivo se reutilizara recolocándolo sobre la nueva galería. Este elemento de madera
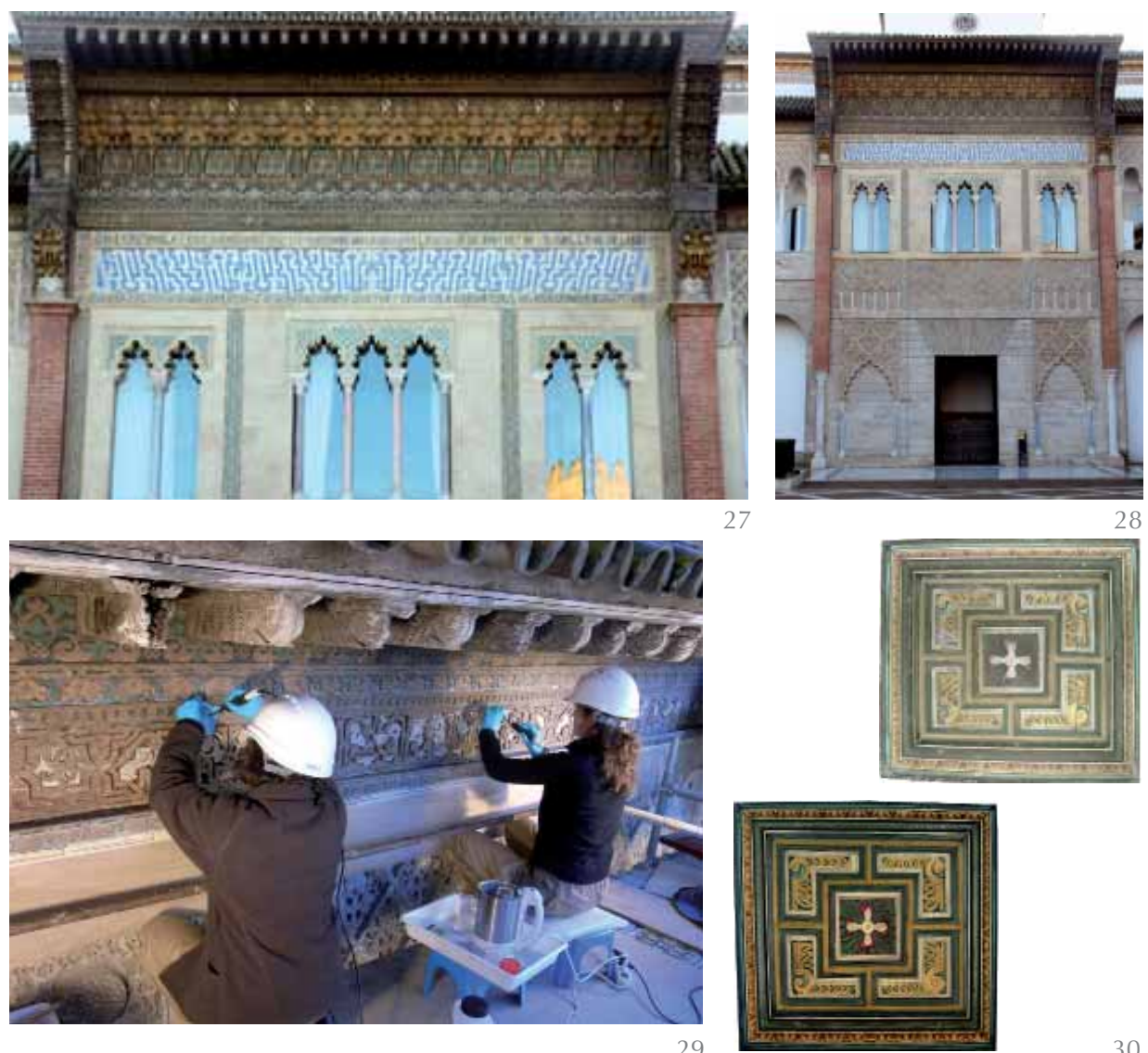
Esto indica que el alero fue totalmente desmontado y remontado con tal motivo. Los análisis de dendrocronología parecen indicar que hubo también una intervención importante en el siglo XVI con sustitución igualmente de algunos elementos.

Las yeserías del cuerpo alto presentaban diversos problemas, tales como suciedad general, sobre todo por acumulación de polvo, y en algunos casos pequeñas grietas e incluso peligro de desprendimiento de algunas de las piezas. Se procedió a afianzar las uniones de los distintos elementos y al sellado de las juntas con materiales que garantizan la homogeneidad de la obra. La limpieza de la suciedad se realizó mediante aspiración y arrastre con brocha y posteriormente mediante medios mecánicos manuales, y en donde ha sido necesario, con reblandecimiento previo con papetas de celulosa impregnadas de disolventes apropiados. Especial atención se prestó a la preservación de los restos de policromía, desgraciadamente muy escasos en las zonas más expuestas a la intemperie, que fueron fijados y consolidados. Finalmente se aplicó a la yesería, especialmente a las zonas más expuestas, una protección hidrofugante (Figura 31).

Se limpiaron igualmente los elementos de mármol tales como columnas, capiteles y alizares. Esta limpieza se realizó con agua $y$ detergentes neutros y en las zonas en que fue necesario, mediante la aplicación de papetas de celulosa impregnadas en disolventes inocuos para la piedra, como bifluoruro de amonio, y mecánicamente, mediante punta de bisturí, en zonas de difícil aplicación y con grandes concentraciones de suciedad.

La limpieza de la fábrica de ladrillo se efectuó por procedimientos mecánicos no abrasivos, como soplado con aire a presión y cepillado con cepillos de púa vegetal blanda. Posteriormente, y según los resultados obtenidos previamente, se usaron otros procedimientos, como el reblandecimiento mediante pulverización acuosa desmineralizada, seguida de limpieza mecánica y,

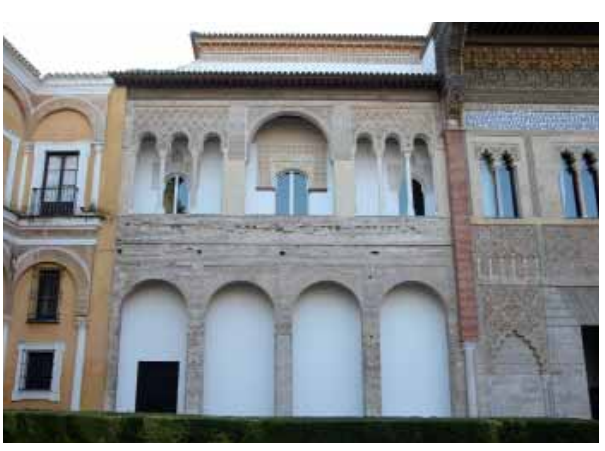

en casos de persistencia de la suciedad, aplicación de papetas de celulosa con disolventes adecuados. También se ha procedido a reponer el rejuntado de mortero de cal en zonas en que estaba perdido.

Como se ha indicado, con carácter previo a la intervención, y después a lo largo de todo el proceso, se ha realizado una labor muy completa de análisis y estudios de la fachada, tanto en lo que respecta a la pintura del alero del cuerpo central, con de las policromías del resto. Actualmente se encuentra muy avanzado el estudio de la evolución cromática de estos elementos realizado en la facultad de Bellas Artes de Granada, en base al estudio de los estratos pictóricos y de la composición de los pigmentos.

Los cinco años de trabajos en la fachada, fruto de la permanente atención que el $\mathrm{Pa}$ tronato del Real Alcázar y la Dirección del monumento prestan a su conservación han permitido no sólo mejorar sus condiciones físicas y recuperar algunos de sus valores estéticos, como es el caso de la policromía de los aleros, sino que también han propiciado la investigación y con ello el mejor conocimiento del edificio.

Los estudios históricos y arqueológicos, las investigaciones sobre la naturaleza y comportamiento de los materiales, los análisis de las policromías y sus modificaciones a lo largo del tiempo, y en general la información pormenorizada que se ha podido obtener durante todas estas intervenciones, amplían notablemente nuestros conocimientos y con ello las posibilidades de conservar para el futuro todos los valores que posee este importantísimo monumento (Figura 32).

Este trabajo se ha realizado en el marco del Proyecto de Investigación del VI Plan $\mathrm{Na}$ cional de Investigación Científica, DesarroIlo e Innovación Tecnológica 2008-2011, titulado "Los palacios en la Baja Edad Media peninsular: intercambios e influencias entre Al-Andalus y los Reinos Cristianos" (HAR2008-01941).

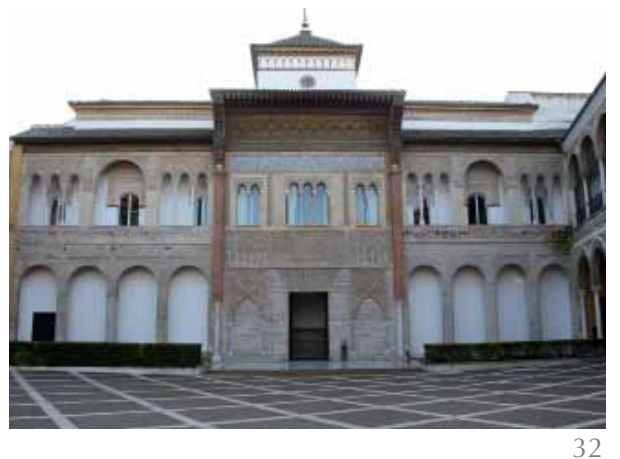

31. El lado izquierdo de la fachada ya restaurado.

32. La fachada del palacio después de su restauración completa. 


\section{BIBLIOGRAFÍA}

(1) Almagro, A.: Planimetría del Alcázar de Sevilla, Sevilla-Granada 2000.

(2) Almagro, A.: "El patio del Crucero de los Reales Alcázares de Sevilla". Al-Qantara XX (1999): 331-376

(3) Almagro, A. (dir.): "El Patio del Crucero del Alcázar de Sevilla". CD interactivo, Granada 2005.

(4) Almagro, A. (dir.): "El Alcázar de Sevilla en el Siglo XIV. The Alcazar of Seville in the 14th Century". Animación en soporte DVD, Granada 2006.

(5) Tabales, M.A. "Investigaciones arqueológicas en el Patio de las Doncellas". Apuntes del Alcázar, 4 (2003) 7-25.

(6) Marín Fidalgo, A.: El Alcázar de Sevilla bajo los Austrias, Sevilla 1990: 134-179, 206-242.

(7) Tabales, M.A.: "El Patio de las Doncellas del Palacio de Pedro I de Castilla. Génesis y Transformación". Apuntes del Alcázar de Sevilla, 6 (2005), p. 6-39.

(8) Casares Porcel, M.; Tito Rojo, J.; Cruces Blanco, E.: "El jardín del Patio de la Acequia del Generalife. I. Su evolución en la documentación escrita y gráfica". Cuadernos de la Alhambra, 39 (2003): 83-86.

(9) Casares Porcel, M.; Tito Rojo, J.; Socorro Abreu, O.: "El jardín del Patio de la Acequia del Generalife. II. Consideraciones a partir del análisis palinológico". Cuadernos de la Alhambra, 39 (2003): 87-107.

(10) Almagro, A. (coord.): "La portada del Palacio de Pedro I. Investigación y restauración". Apuntes de Alcázar de Sevilla, 10 (2009), p. 7-49. 